\title{
Correct recognition and continuum belief of mental disorders in a nursing student population
}

Lee Seng Esmond Seow ${ }^{1 *}$ D, Boon Yiang Chua ${ }^{1}$, Huiting Xie², Jia Wang ${ }^{2}$, Hui Lin Ong ${ }^{1}$, Edimansyah Abdin ${ }^{1}$, Siow Ann Chong ${ }^{1}$ and Mythily Subramaniam ${ }^{1}$

\begin{abstract}
Background: The current study aimed to explore the correct recognition of mental disorders across dementia, alcohol abuse, obsessive compulsive disorder (OCD), schizophrenia and depression, along with its correlates in a nursing student population. The belief in a continuum of symptoms from mental health to mental illness and its relationship with the non-identification of mental illness was also explored.

Methods: Five hundred students from four nursing institutions in Singapore participated in this cross-sectional online study. Respondents were randomly assigned to a vignette describing one of the five mental disorders before being asked to identify what the person in the vignette is suffering from. Continuum belief was assessed by rating their agreeableness with the following statement: "Sometimes we all behave like X. It is just a question of how severe or obvious this condition is".

Results: OCD had the highest correct recognition rate (86\%), followed by depression (85\%), dementia (77\%), alcohol abuse (58\%) and schizophrenia (46\%). For continuum belief, the percentage of respondents who endorsed symptom continuity were 70\% for depression, 61\% for OCD, 58\% for alcohol abuse, 56\% for dementia and 46\% for schizophrenia. Of concern, we found stronger continuum belief to be associated with the non-identification of mental illness after controlling for covariates.

Conclusions: There is a need to improve mental health literacy among nursing students. Almost a quarter of the respondents identified excessive alcohol drinking as depression, even though there was no indication of any mood symptom in the vignette on alcohol abuse. Further education and training in schizophrenia may need to be conducted. Healthcare trainees should also be made aware on the possible influence of belief in symptom continuity on one's tendency to under-attribute mental health symptoms as a mental illness.
\end{abstract}

\section{Background}

Mental health literacy (MHL) is the knowledge and beliefs about mental disorders that influence recognition, treatment and prevention. The US Institute of Medicine (IoM) defined health literacy as "the degree to which individuals have capacity to obtain, process and understand basic health information and services needed to make appropriate health decisions" [1]. Close to 50\% of the US population reported lifetime prevalence of at least one mental disorder while nearly $30 \%$ reported at

\footnotetext{
* Correspondence: esmond_LS_SEOW@imh.com.sg

${ }^{1}$ Research Division, Institute of Mental Health, Singapore, Singapore

Full list of author information is available at the end of the article
}

least one 12-month mental disorder [2]. The Global Burden of Disease Study (GBD 2010) estimated that mental, neurological and substance use disorders accounted for $10.4 \%$ of global disability-adjusted life years (DALYs), 2.3\% of global years of life (YLLs) lost to premature mortality and $28.5 \%$ of global years lived with disability (YLDs), making them the leading cause of YLDs [3]. With the high prevalence and the significant proportion of disease burden due to mental illnesses, the concept of mental health literacy thus becomes crucial as knowledge about mental health diseases serves as a prerequisite for early recognition and intervention in mental disorders. 
Studies have shown that many members of the public cannot understand the meaning of psychiatric terms or correctly recognize mental health problems $[4,5]$. Physicians and healthcare professionals therefore play an important role in detecting mental disorders in the society as they are the individuals whom the public will first seek help and treatment from. However, mental health problems and existing mental disorders often remain undiagnosed in the primary care setting [6,7]. In one study, only $23 \%$ of a surgical patient population was accurately identified by the surgeons and nurses for their substance abuse, with the lack of time and knowledge being the reasons for this low recognition rate [8]. In addition, patients may often present with somatic complaints that mimic those of a diagnosed medical condition, hence complicating the diagnosis of a mental disorder. This is evident in the case of diagnosing depression among elderly, where the similarity of symptoms of depression to those of dementia, or the presence of a medical condition may override the symptoms of depression [9]. A mental health literacy study among psychiatrically and generally trained nurses employed in a psychiatric hospital has also revealed that despite the training received, the depression vignette was commonly defined as "stress" instead of a psychiatric diagnosis [10]. Those in the field of medicine or nursing have since realized the importance of mental health literacy and have embarked on more proactive approaches in educating and training healthcare students in the area of psychiatry and mental health [11].

Mental health has been traditionally believed to exist on a continuum, with mental well-being at one end of the continuum and mental illness at the other end. Evidence has shown that one can suffer from symptoms of mental illness on a continuum [12, 13]. In other words, while a proportion of the general population might not have met the criteria for a full blown mental disorder, they would have experienced one or more symptoms associated with mental disorders during their lifetime. Studies have also found the belief in a continuum of symptom experience to be associated with less stigmatizing attitudes towards those with mental illnesses [14, 15]. Stigmatization of mental illness has been conceptualized as a process of multiple, interrelated steps and central to this, it is the separation between "us" and "them" that leads to the negative emotional reactions and eventually, discrimination and devaluation of the person with mental illness [16]. Individuals who endorsed stronger continuum belief or agreed that mental health problems are also experienced by many, sometimes are less likely to perceive this differentness between those with and without mental illnesses. In line with this notion, stronger continuum belief could also possibly cloud one's likelihood to diagnose someone who develops signs and symptoms of mental health problems as having a clinically significant mental disorder. Therefore, we hypothesized that stronger continuum belief would be linked to the non-identification of mental illness in our study.

The current study therefore aimed to examine: (1) the correct recognition rates and continuum beliefs of psychiatric symptoms across five diagnostic conditions namely dementia, alcohol abuse, obsessive compulsive disorder (OCD), schizophrenia and depression, (2) the correlates of correct recognition, (3) the correlates of continuum belief and finally, (4) the relationship between continuum belief and non-identification of mental illness in a nursing student population in Singapore.

\section{Methods}

\section{Study participants}

Students enrolled in four nursing institutions in Singapore were invited to take part in a web-based survey via school email or verbal dissemination by staff personnel during class. A total of 500 students were recruited from the period of April to July 2016. Quota limits were set to ensure adequate participation of students from each of the institutions and across their academic years. Implicit informed consent was obtained. The study was approved by the ethics committee of the relevant institutional review board. Participants received a Starbucks card with monetary value of $\$ 20$ upon completion of the study.

\section{Questionnaire}

Sociodemographic data (age, gender, ethnicity, household income, current education, professional year) and other information pertaining to the mode of their training in psychiatric nursing (e.g., lecture and small group teaching, clinical placement) were collected using a structured questionnaire. A vignette based approach modeled on the Depression Literacy Questionnaire by Jorm et al. (1997) [5] was adopted to determine the level of mental health literacy among the target study population. Participants were presented with a vignette describing an individual " $\mathrm{X}$ " with a specific disorder before completing subsequent questions. They were asked to indicate if they feel the symptoms described in the given vignette were a cause for concern or worry, followed by responding to an open-ended question on what they think $\mathrm{X}$ is suffering from. Next, participants were further asked to rate their agreeableness with the following statement: "Sometimes we all behave like X. It is just a question of how severe or obvious this condition is" on a 5-point Likert-scale from (1) strongly disagree to (5) strongly agree. A higher score indicates stronger belief in a continuum of symptom experience. Lastly, they were asked if anyone in their family or close circle of friends ever had problems 
similar to $\mathrm{X}$ and if they had any experience (e.g., volunteering, training) in dealing with a person who has a problem like $\mathrm{X}$ for the respective vignette they received.

\section{Vignettes}

A total of five vignettes were used for the current study to describe dementia, alcohol abuse, OCD, schizophrenia and depression. These vignettes were developed through consultation with experienced research psychiatrists and approved by a panel of senior clinical psychiatrists to ensure that each disorder satisfied the DSM-IV criteria. Detailed information on the development of these vignettes can be found in a study conducted among the general population in Singapore [17]. Depression, alcohol abuse and OCD were selected as they were identified as the top three most prevalent disorders in the local population [18] while dementia and schizophrenia were included as local data has also made a strong case for their early detection and treatment $[19,20]$. To eliminate inter observer variations and biases, the five vignettes were randomly assigned by the computer to the participants such that each participant only received one vignette and each vignette was administered to 100 participants. Chi-squared analyses were run separately to confirm the absence of unequal distribution of vignette allocation across all sociodemographic and education related factors among the participants.

\section{Coding of open-ended responses}

Response was coded as "Correct recognition" if the respondent was able to accurately name the specific condition. In the case of an ambiguous response, two of the authors (ES and MS) would come to a consensus on how the response would be coded. "Disorder specific symptoms" refers to amnesia, short term memory, confusion for dementia, germophobia, anxiety for OCD, and hallucinations, delusions, paranoia for schizophrenia. "Not an illness" refers to, for example, the lack of selfcontrol, anger management problem, or feelings of insecurity and anxiousness. The response categories reported include only those that have been endorsed by at least $5.0 \%$ of the students in a single vignette.

\section{Power calculation and statistical analyses}

Based on a previous study looking at the mental health literacy conducted in the general population in Singapore [17], the overall correct recognition rate of specific conditions was $43.7 \%$ using single proportion formula with precision set at 5\%. A sample size of 378 participants would therefore be required to ensure adequate power for the study. In all, 500 responses were received from all the institutions and included for further analysis. Statistical analyses were performed using IBM SPSS, version 23. Descriptive statistics were tabulated for the overall sample. Frequency and percentage were calculated for categorical variables, while mean and standard deviation were calculated for all other continuous variables. Multiple logistic regression was performed to determine correlates of correct recognition of mental disorders while multiple linear regression was conducted to examine the correlates of continuum belief (belief that problem is also experienced by others) in our sample. We have also examined the relationship between continuum belief and the non-identification of mental illness after adjusting for covariates using multiple logistic regression. Statistical significance was set at $p<0.05$ level.

\section{Results}

The characteristics of the sample are displayed in Table 1. The majority of the students were in the younger age group ( $<21$ years old), females, Chinese and had a monthly household income of $\$ 4000$ and above. A large proportion of students undertaking diploma certification were recruited as they represent the bulk of the nursing student population in Singapore. Most of them had completed their psychiatric nursing training through lectures and small group teaching (79.8\%), as well as clinical placement (60.6\%). 25.0\% had an experience dealing (e.g., through volunteering, training) with someone like the person they had read about in their assigned vignette while $34.8 \%$ of them had friends or family members with problems similar to person "X".

Table 2 shows the percentage of students mentioning each category to describe the problem in the vignette assigned to them. The correct recognition rates across the five vignettes- dementia, alcohol abuse, OCD, schizophrenia and depression were $77.0 \%, 58.0 \%, 86.0 \%$, $46.0 \%$ and $85.0 \%$ respectively. 'Depression' was the term used most often to describe the other four vignettes (apart from their correct recognition and disorder specific symptoms), with $23.0 \%$ describing "alcohol abuse" as such. The person $\mathrm{X}$ in the "dementia" and "alcohol abuse" vignette were described as suffering from a medical problem by $1.0 \%$ and $3.0 \%$ of their respective sample and these were rated under irrelevant responses.

Table 3 shows the correlates of correct recognition in the sample. Those of the Malay ethnicity were less likely to correctly identify the mental disorder compared to the Chinese. Nursing school factors such as the years spent in nursing education or the training in psychiatric nursing (e.g., the attendance of clinical placement, lecture and small group teaching) were not significantly associated with the correct recognition of mental disorders. All four vignettes- depression, dementia, OCD and alcohol abuse had higher odds of being correctly recognized compared to the schizophrenia vignette. Those having experience dealing with someone who had a problem similar to the assigned vignette were also 
Table 1 Profile of study participants $(N=500)$

\begin{tabular}{|c|c|c|c|}
\hline & & $n$ & $\%$ \\
\hline \multirow[t]{2}{*}{ Age group } & $<21$ years & 334 & 66.8 \\
\hline & 21 years and above & 166 & 33.2 \\
\hline \multirow[t]{2}{*}{ Gender } & Male & 83 & 16.6 \\
\hline & Female & 417 & 83.4 \\
\hline \multirow[t]{3}{*}{ Ethnicity } & Chinese & 287 & 57.4 \\
\hline & Malay & 134 & 26.8 \\
\hline & Indian and Others & 79 & 15.8 \\
\hline \multirow[t]{3}{*}{ Monthly household income(\$) } & Below 2000 & 158 & 31.6 \\
\hline & 2000-3999 & 160 & 32.0 \\
\hline & 4000 and above & 182 & 36.4 \\
\hline \multirow[t]{3}{*}{ Education } & Vocational & 100 & 20.0 \\
\hline & Diploma & 300 & 60.0 \\
\hline & Tertiary & 100 & 20.0 \\
\hline \multirow{5}{*}{$\begin{array}{l}\text { Stage of nursing education } \\
\text { (years spent in nursing education) }\end{array}$} & $1^{\text {st }}$ year & 147 & 29.4 \\
\hline & $2^{\text {nd }}$ year & 166 & 33.2 \\
\hline & $3^{\text {rd }}$ year & 102 & 20.4 \\
\hline & $4^{\text {th }}$ year & 63 & 12.6 \\
\hline & $5^{\text {th }}$ year & 22 & 4.4 \\
\hline \multirow[t]{2}{*}{ Lecture and small group teaching } & Attended & 399 & 79.8 \\
\hline & Not attended & 101 & 20.2 \\
\hline \multirow[t]{2}{*}{ Clinical placement } & Attended & 303 & 60.6 \\
\hline & Not attended & 197 & 39.4 \\
\hline \multirow{2}{*}{$\begin{array}{l}\text { Has experience dealing with someone } \\
\text { having problems similar to " } \mathrm{X} \text { " }\end{array}$} & Yes & 125 & 25.0 \\
\hline & No & 375 & 75.0 \\
\hline \multirow{2}{*}{$\begin{array}{l}\text { Has friends and family with problems } \\
\text { similar to " } X \text { " }\end{array}$} & Yes & 174 & 34.8 \\
\hline & No & 326 & 65.2 \\
\hline
\end{tabular}

more likely to correctly recognize the mental disorder compared to their counterparts.

Table 4 presents the correlates of continuum belief of mental disorders. Our findings revealed that students in the $2^{\text {nd }}$ and $4^{\text {th }}$ year of their nursing education were less likely to endorse a belief in a continuum of symptom experience compared to $1^{\text {st }}$ year students. Those who received the depression and OCD vignettes were morely likely to perceive a continuum of symptom experienced than those who received the schizophrenia vignette. In addition, those who had close friends and family members with problems similar to " $\mathrm{X}$ " were more likely to have stronger continnum belief than those without.

A total of 65 participants (13.0\%) in the entire sample did not identify the condition in the vignette as a mental illness and these include those in the categories of "disorder specific symptoms", "psychosocial stress", "not an illness", and "not sure/irrelevant response". After controlling for all confounding variables, we found higher continuum belief score to be significantly associated with the identification of the condition in the assigned vignette as a non- mental disorder (Table 5). Compared to all other vignettes-depression, dementia, OCD and alcohol abuse-schizophrenia was also less likely to be recognized as a mental disorder.

\section{Discussion}

The current study seeks to explore the recognition and perception of mental disorders within the nursing student population in Singapore via a vignette approach. Comparison was made across five diagnoses namely depression, dementia, OCD, alcohol abuse and schizophrenia, which were selected for reasons such as their prevalence and clinical impact within the local general population.

\section{Correct recognition of mental disorders}

Expectedly, our study revealed higher correct recognition rates across most diagnoses among the nursing students compared to the general population in Singapore who were assigned the same vignettes in another study [17]. The greatest difference was reported in the vignette for OCD $(86.0 \%$ vs $28.7 \%)$, followed by schizophrenia ( $46.0 \%$ vs $11.5 \%)$, depression $(85.0 \%$ vs $55.2 \%)$, and dementia $(77.0 \%$ vs $66.3 \%)$. The recognition rates for alcohol abuse were almost similar (58.0\% vs $57.1 \%)$.

The recognition for schizophrenia was the lowest among the five mental disorders in the nursing population with less than $50 \%$ of them being able to correctly recognise it. While the recognition for schizohprenia was also the lowest in the general population compared to the other four diagnoses [17], trained nurses at a psychiatric hospital were able to more accurately diagnose schizophrenia compared to depression and mania [10]. Near to a fifth of the students were able to identify at least one of the symptoms such as hallucination or delusion presented in the entire vignette but did not recognise $\mathrm{X}$ as suffering from schizophrenia nor a mental illness. Despite being the vignette associated with the lowest continnum belief score (i.e., we do not tend to behave like $\mathrm{X}$ ), students also did not seem to recognize schizophrenia as a mental disorder compared to the other four vignettes contrary to our hypothesis. This may suggest a critical lack of understanding for schizophrenia as a mental disorder in this group despite the training in psychiatric nursing received.

It was noteworthy, that the nursing students did not perform much better in term of their recognition for the alcohol abuse vignette. Almost a quarter of the students who received the vignette on alcohol abuse/dependence misidentified the excessive alcohol drinking as depression even though there was no indication of any mood symptom within the vignette passage. These students 
Table 2 Problem description by the nursing students based on vignette assigned, $n$ (\%)

\begin{tabular}{|c|c|c|c|c|c|c|}
\hline & $\begin{array}{l}\text { Overall } \\
(N=500)\end{array}$ & $\begin{array}{l}\text { Dementia } \\
(n=100)\end{array}$ & $\begin{array}{l}\text { Alcohol abuse } \\
(n=100)\end{array}$ & $\begin{array}{l}\text { OCD } \\
(n=100)\end{array}$ & $\begin{array}{l}\text { Schizophrenia } \\
(n=100)\end{array}$ & $\begin{array}{l}\text { Depression } \\
(n=100)\end{array}$ \\
\hline \multicolumn{7}{|l|}{ Recognition } \\
\hline 1. Correct recognition & $352(70.4)$ & $77(77.0)$ & $58(58.0)$ & $86(86.0)$ & $46(46.0)$ & $85(85.0)$ \\
\hline 2. Disorder specific symptoms & $33(6.6)$ & $8(8.0)$ & - & $6(6.0)$ & $17(17.0)$ & $2(2.0)$ \\
\hline 3. Other mental disorder- any anxiety disorder & $11(2.2)$ & $1(1.0)$ & $4(4.0)$ & - & $5(5.0)$ & $1(1.0)$ \\
\hline 4. Other mental disorder- depression & $43(8.6)$ & $7(7.0)$ & $23(23.0)$ & $4(4.0)$ & $9(9.0)$ & - \\
\hline 5. Other mental disorder- miscellaneous & $17(3.4)$ & $1(1.0)$ & $3(3.0)$ & $4(4.0)$ & $7(7.0)$ & $2(2.0)$ \\
\hline 6. Mental illness & $12(2.4)$ & $2(2.0)$ & $1(1.0)$ & - & $7(7.0)$ & $2(2.0)$ \\
\hline 7. Psychosocial stress & $8(1.6)$ & - & $2(2.0)$ & - & $1(1.0)$ & $5(5.0)$ \\
\hline 8. Not an illness & $15(3.0)$ & $1(1.0)$ & $6(6.0)$ & & $5(5.0)$ & $3(3.0)$ \\
\hline 9. Not sure/irrelevant response & $9(1.8)$ & $3(3.0)$ & $3(3.0)$ & - & $3(3.0)$ & - \\
\hline \multicolumn{7}{|c|}{ Continuum Belief- believes problem is also experienced by many, sometimes } \\
\hline Agree & $291(58.2)$ & $56(56.0)$ & $58(58.0)$ & $61(61.0)$ & $46(46.0)$ & $70(70.0)$ \\
\hline Disagree & $106(21.2)$ & $19(19.0)$ & $21(21.0)$ & $20(20.0)$ & $33(33.0)$ & $13(13.0)$ \\
\hline Undecided & $103(20.6)$ & $25(25.0)$ & $21(21.0)$ & 19 (19.0) & $21(21.0)$ & $17(17.0)$ \\
\hline Mean score (S.D.) & $3.44(1.08)$ & $3.45(0.99)$ & $3.41(1.08)$ & 3.58 (1.17) & $3.08(1.12)$ & $3.69(0.95)$ \\
\hline
\end{tabular}

might have possibly looked beyond the presenting symptoms and perceived depression as the the underlying cause for the alcohol abuse. In other words, the drinking behavior was deemed to be a sign of depression, instead of being a disorder itself. In addition, the misidentification could be influenced by their knowledge of the high comorbidity and strong association between alcohol use disorder and depression based on past research studies [21-23]. While the identification of either depression or alcohol use disorder should lead to further inquiry into the symptoms of the other in clinical practice, the problem of misdiagnosis may impede the formulation and delivery of effective treatment for individuals with alcohol use disorder. This can have significant potential implications for healthcare providers.

Our analysis also revealed that students of the Malay ethnicity were less likely to correctly identify the mental disorders compared to the students of Chinese ethnicity. Again, this phenomenon has also been reflected in the general population where the Malays and the Indians were more likely to describe certain disorders such as dementia as "not a disorder" or use disorder specific symptoms [17]. One possibility suggested was that these ethnic groups may have normalized or attributed the manifestations of certain mental disorders to reasons other than a disease state. Data in our sample also suggests that Malay students tend not to recognise the vignettes as mental disorders compared to the Chinese although this is not significant $(p=0.092)$. Nevertheless, more research would need to be done to explore the underlying causes or tendencies for such ethnic differences in the recognition of mental problems.

\section{Continuum belief of mental disorders and its association} with mental illness identification

While comparing continuum belief across the five mental diagnoses, we found the percentage of those who believe in a continuum of symptoms to be the lowest for schizophrenia compared to the other conditionsschizophrenia $(46.0 \%)$ followed by dementia $(56.0 \%)$, alcohol abuse (58.0\%), OCD (61.0\%), and depression (70.0\%). Compared to the data from the general population in Singapore, the finding is almost similar in terms of their order (except dementia) but not the magnitude: schizophrenia (32.7\%), alcohol abuse (35.6\%), OCD (36.8\%), dementia (46.8\%) and depression (57.9\%) [24]. Other studies have also found a lower agreement or percentage of respondents who belived in a symptom continuity for schizophrenia compared to depression $[14,15,25]$. The symptom continuity score for alcohol abuse was the next lowest after schizophrenia. The percentages of respondents who agreed with symptom continuity were found to be similar for schizophrenia (26\%) and alcohol abuse (27\%) in one study [14]. It is noteworthy that a higher proportion of students agreed with symptom continuum (70\% for depression and $46 \%$ for schizophrenia) compared to those in the populations surveys including that of Singapore's (42\% and $26 \%$ respectively in Germany; $58.2 \%$ and $28.5 \%$ respectively in France) $[14,24,25]$. One possible reason might be that nursing students have more opportunities for exposure to individuals with mental illnesses during their course of study, hence resulting in higher endorsement of symptom continuum compared to the general population. 
Table 3 Correlates of correct recognition of mental disorders $(N=500)$

\begin{tabular}{|c|c|c|c|c|c|}
\hline \multirow{2}{*}{ Age group } & \multirow[b]{2}{*}{$<21$ years } & \multirow{2}{*}{$\frac{\text { OR }}{\text { Ref. }}$} & \multicolumn{2}{|c|}{$95 \% \mathrm{Cl}$} & \multirow{2}{*}{$\frac{p \text {-value }}{-}$} \\
\hline & & & - & - & \\
\hline & $\begin{array}{l}21 \text { years and } \\
\text { above }\end{array}$ & 1.424 & 0.783 & 2.590 & 0.247 \\
\hline \multirow[t]{2}{*}{ Gender } & Female & Ref. & - & - & - \\
\hline & Male & 0.636 & 0.358 & 1.130 & 0.123 \\
\hline \multirow[t]{3}{*}{ Ethnicity } & Chinese & Ref. & - & - & - \\
\hline & Malay & 0.422 & 0.242 & 0.738 & 0.002 \\
\hline & $\begin{array}{l}\text { Indian and } \\
\text { Others }\end{array}$ & 0.550 & 0.290 & 1.044 & 0.068 \\
\hline \multirow{3}{*}{$\begin{array}{l}\text { Monthly household } \\
\text { income }\end{array}$} & Below 2000 & Ref. & - & - & - \\
\hline & 2000-3999 & 0.899 & 0.517 & 1.561 & 0.705 \\
\hline & 4000 and above & 0.622 & 0.357 & 1.082 & 0.093 \\
\hline \multirow[t]{3}{*}{ Education } & Vocational & Ref. & - & - & - \\
\hline & Diploma & 0.813 & 0.427 & 1.548 & 0.528 \\
\hline & Tertiary & 1.622 & 0.665 & 3.954 & 0.287 \\
\hline \multirow{5}{*}{$\begin{array}{l}\text { Stage of nursing } \\
\text { education }\end{array}$} & $1^{\text {st }}$ year & Ref. & - & - & - \\
\hline & $2^{\text {nd }}$ year & 1.251 & 0.634 & 2.467 & 0.518 \\
\hline & $3^{\text {rd }}$ year & 2.224 & 0.877 & 5.637 & 0.092 \\
\hline & $4^{\text {th }}$ year & 1.045 & 0.408 & 2.680 & 0.926 \\
\hline & $5^{\text {th }}$ year & 1.242 & 0.316 & 4.889 & 0.756 \\
\hline \multirow{2}{*}{$\begin{array}{l}\text { Lecture and small } \\
\text { group teaching }\end{array}$} & Attended & Ref. & - & - & - \\
\hline & Not attended & 1.511 & 0.781 & 2.926 & 0.220 \\
\hline \multirow[t]{2}{*}{ Clinical placement } & Attended & Ref. & - & - & - \\
\hline & Not attended & 0.971 & 0.489 & 1.930 & 0.933 \\
\hline \multirow[t]{5}{*}{ Vignette type } & Schizophrenia & Ref. & - & - & - \\
\hline & Depression & 8.427 & 3.985 & 17.822 & $<0.001$ \\
\hline & Dementia & 4.587 & 2.342 & 8.982 & $<0.001$ \\
\hline & OCD & 9.610 & 4.576 & 20.179 & $<0.001$ \\
\hline & Alcohol abuse & 1.845 & 1.002 & 3.396 & 0.049 \\
\hline \multirow{2}{*}{$\begin{array}{l}\text { Has experience dealing } \\
\text { with someone having } \\
\text { problems similar to " } \mathrm{X} \text { " }\end{array}$} & No & Ref. & - & - & - \\
\hline & Yes & 1.868 & 1.126 & 3.097 & 0.015 \\
\hline \multirow{2}{*}{$\begin{array}{l}\text { Has friends and family } \\
\text { with problems similar } \\
\text { to " } X \text { " }\end{array}$} & No & Ref. & - & - & - \\
\hline & Yes & 1.477 & 0.837 & 2.605 & 0.178 \\
\hline
\end{tabular}

Cl confidence interval, $O R$ odds ratio

Our data also suggested that among nursing students who have close friends and family with problems similar to " $\mathrm{X}$ " (but not those who have experience dealing with someone like " $\mathrm{X}$ "), were more likely to endorse greater continuum belief than their counterparts. Again, this result may not be surprising given that long term exposure may play an important role in shaping beliefs and attitudes. Prolonged and intimate exposure has been suggested to lead to a positive attitudinal or perceptual change towards mental illness with improved benevolence
Table 4 Correlates of continuum belief of mental disorders $(N=500)$

\begin{tabular}{|c|c|c|c|c|c|}
\hline & & $\beta$ & $95 \% \mathrm{Cl}$ & & $p$-value \\
\hline \multirow[t]{2}{*}{ Age group } & $<21$ years & Ref. & - & - & - \\
\hline & $\begin{array}{l}21 \text { years and } \\
\text { above }\end{array}$ & -0.090 & -0.337 & 0.158 & 0.476 \\
\hline \multirow[t]{2}{*}{ Gender } & Female & Ref. & - & - & - \\
\hline & Male & -0.005 & -0.257 & 0.246 & 0.966 \\
\hline \multirow[t]{3}{*}{ Ethnicity } & Chinese & Ref. & - & - & - \\
\hline & Malay & 0.009 & -0.230 & 0.248 & 0.940 \\
\hline & $\begin{array}{l}\text { Indian and } \\
\text { Others }\end{array}$ & -0.054 & -0.331 & 0.222 & 0.700 \\
\hline \multirow{3}{*}{$\begin{array}{l}\text { Monthly household } \\
\text { income }\end{array}$} & Below 2000 & Ref. & - & - & - \\
\hline & 2000-3999 & 0.039 & -0.194 & 0.272 & 0.743 \\
\hline & $\begin{array}{l}4000 \text { and } \\
\text { above }\end{array}$ & -0.073 & -0.303 & 0.158 & 0.535 \\
\hline \multirow[t]{3}{*}{ Education } & Vocational & Ref. & - & - & - \\
\hline & Diploma & 0.161 & -0.125 & 0.448 & 0.269 \\
\hline & Tertiary & 0.059 & -0.307 & 0.426 & 0.750 \\
\hline \multirow{5}{*}{$\begin{array}{l}\text { Stage of nursing } \\
\text { education }\end{array}$} & $1^{\text {st }}$ year & Ref. & - & - & - \\
\hline & $2^{\text {nd }}$ year & -0.299 & -0.595 & -0.003 & 0.047 \\
\hline & $3^{\text {rd }}$ year & -0.061 & -0.458 & 0.336 & 0.763 \\
\hline & $4^{\text {th }}$ year & -0.431 & -0.832 & -0.030 & 0.035 \\
\hline & $5^{\text {th }}$ year & 0.227 & -0.372 & 0.826 & 0.457 \\
\hline \multirow{2}{*}{$\begin{array}{l}\text { Lecture and small } \\
\text { group teaching }\end{array}$} & Attended & Ref. & - & - & - \\
\hline & Not attended & -0.103 & -0.376 & 0.169 & 0.456 \\
\hline \multirow[t]{2}{*}{ Clinical placement } & Attended & Ref. & - & - & - \\
\hline & Not attended & 0.129 & -0.167 & 0.426 & 0.393 \\
\hline \multirow[t]{5}{*}{ Vignette type } & Schizophrenia & Ref. & - & - & - \\
\hline & Depression & 0.415 & 0.116 & 0.714 & 0.007 \\
\hline & Dementia & 0.234 & -0.064 & 0.532 & 0.123 \\
\hline & OCD & 0.449 & 0.156 & 0.742 & 0.003 \\
\hline & Alcohol abuse & 0.262 & -0.032 & 0.557 & 0.081 \\
\hline \multirow{2}{*}{$\begin{array}{l}\text { Has experience dealing } \\
\text { with someone having } \\
\text { problems similar to " } \mathrm{X} \text { " }\end{array}$} & No & Ref. & - & - & - \\
\hline & Yes & -0.133 & -0.339 & 0.072 & 0.202 \\
\hline \multirow{2}{*}{$\begin{array}{l}\text { Has friends and family } \\
\text { with problems similar } \\
\text { to " } \mathrm{\text {" }}\end{array}$} & No & Ref. & - & - & - \\
\hline & Yes & 0.413 & 0.189 & 0.638 & $<0.001$ \\
\hline
\end{tabular}

Cl confidence interval, $\beta$ beta coefficient

(the view that the person is suffering psychologically, due to their misfortune, should be the subject of a kind and paternalistic protectionism based on care, personal attention, and material comfort), mental hygiene ideology (the idea that the person suffering from mental illness is similar to normal people, but with quantitative rather than qualitative differences) and interpersonal aetiology (the belief that the real cause of a mental illness are the problematic interpersonal relations) [26, 27]. 
Table 5 Relationship between continuum belief and the non-identification of mental illness

\begin{tabular}{|c|c|c|c|c|c|}
\hline \multirow{2}{*}{ Continuum belief score } & & \multirow{2}{*}{$\frac{\mathrm{OR}}{1.360}$} & \multicolumn{2}{|c|}{$95 \% \mathrm{Cl}$} & \multirow{2}{*}{$\frac{p \text {-value }}{0.042}$} \\
\hline & & & 1.011 & 1.829 & \\
\hline \multirow[t]{2}{*}{ Age group } & $<21$ years & Ref. & - & - & - \\
\hline & $\begin{array}{l}21 \text { years and } \\
\text { above }\end{array}$ & 0.686 & 0.309 & 1.523 & 0.354 \\
\hline \multirow[t]{2}{*}{ Gender } & Female & Ref. & - & - & - \\
\hline & Male & 1.899 & 0.938 & 3.842 & 0.075 \\
\hline \multirow[t]{3}{*}{ Ethnicity } & Chinese & Ref. & - & - & - \\
\hline & Malay & 1.830 & 0.907 & 3.692 & 0.092 \\
\hline & $\begin{array}{l}\text { Indian and } \\
\text { Others }\end{array}$ & 1.850 & 0.813 & 4.213 & 0.143 \\
\hline \multirow{3}{*}{$\begin{array}{l}\text { Monthly household } \\
\text { income }\end{array}$} & Below 2000 & Ref. & - & - & - \\
\hline & 2000-3999 & 0.541 & 0.256 & 1.143 & 0.108 \\
\hline & 4000 and above & 1.176 & 0.605 & 2.285 & 0.663 \\
\hline \multirow[t]{3}{*}{ Education } & Vocational & Ref. & - & - & - \\
\hline & Diploma & 1.252 & 0.566 & 2.768 & 0.578 \\
\hline & Tertiary & 1.047 & 0.340 & 3.227 & 0.936 \\
\hline \multirow{4}{*}{$\begin{array}{l}\text { Stage of nursing } \\
\text { education }^{a}\end{array}$} & $1^{\text {st }}$ year & Ref. & - & - & - \\
\hline & $2^{\text {nd }}$ year & 0.882 & 0.389 & 1.999 & 0.764 \\
\hline & $3^{\text {rd }}$ year & 0.456 & 0.142 & 1.469 & 0.188 \\
\hline & $4^{\text {th }}$ year & 1.129 & 0.358 & 3.560 & 0.837 \\
\hline \multirow{2}{*}{$\begin{array}{l}\text { Lecture and small } \\
\text { group teaching }\end{array}$} & Attended & Ref. & - & - & - \\
\hline & Not attended & 0.677 & 0.303 & 1.513 & 0.342 \\
\hline \multirow[t]{2}{*}{ Clinical placement } & Attended & Ref. & - & - & - \\
\hline & Not attended & 1.512 & 0.655 & 3.492 & 0.333 \\
\hline \multirow[t]{5}{*}{ Vignette type } & Schizophrenia & Ref. & - & - & - \\
\hline & Depression & 0.266 & 0.111 & 0.636 & 0.003 \\
\hline & Dementia & 0.346 & 0.152 & 0.790 & 0.012 \\
\hline & OCD & 0.133 & 0.049 & 0.363 & $<0.001$ \\
\hline & Alcohol abuse & 0.289 & 0.126 & 0.664 & 0.003 \\
\hline \multirow{2}{*}{$\begin{array}{l}\text { Has experience dealing } \\
\text { with someone having } \\
\text { problems similar to " } \mathrm{X} \text { " }\end{array}$} & No & Ref. & - & - & - \\
\hline & Yes & 0.710 & 0.367 & 1.373 & 0.309 \\
\hline \multirow{2}{*}{$\begin{array}{l}\text { Has friends and family } \\
\text { with problems similar } \\
\text { to " } X \text { " }\end{array}$} & No & Ref. & - & - & - \\
\hline & Yes & 0.535 & 0.247 & 1.160 & 0.113 \\
\hline
\end{tabular}

${ }^{a}$ OR was not estimated for $5^{\text {th }}$ year students $(n=22)$ due to zero case endorsing non-mental illness

All variables except continuum belief score were entered into the logistic regression model as covariates

$\mathrm{Cl}$ confidence interval, $O R$ odds ratio

Individuals with mental illness are often recognized as "strangers" and will remain a stranger when there is a lack of available cognitive patterns of interpretation. However, personal contact with affected individuals allows one to gain better awareness on the causes, symptoms and treatment options of mental disorders and thus provides one with the interpretational patterns to eliminate the recognized strangeness from mentally ill patients and eventually making him or her, an accepted other member [28]. On the other hand, our study found a negative association between years spent in nursing education and continuum belief score. The relationship between years of nursing education and continuum belief has not been well-researched and it is unknown why more experienced nursing students are less likely to endorse symptom continuity for mental disorders. Further research is needed to understand this.

Our study may be the first to examine the association between continuum belief and the identification of mental illness. Our study revealed higher continuum belief score to be associated with the identification of person " $\mathrm{X}$ " as not having a mental disorder or vice versa after controlling for possible covariates. Studies looking at the relationship with stigmatization used the belief in continuity of mental illness symptoms as a proxy for separation between "us" and "them" proposed that those who endorsed stronger belief tend to show reduced stigma and less negative atittudes towards individuals with mental illness [14, 15, 25, 29]. Our study suggested that those who endorsed strong continuum belief may not even identify those individuals experiencing the given mental health symptoms as having a mental disorder, and instead may perceive it as the extreme end of symptoms perceived by the population in general, leading to lower stigmatizing attitudes and higher acceptance. Nonetheless, on a negative note, this finding has an important implication as it may suggest that healthcare trainees who endorse strong continuum belief are less likely to see mental health symptoms experienced by one to be a manifestation of a mental disorder, and are hence, unlikely to refer these individuals for psychiatric treatment.

The strengths of the study include that it has recruited a good representative of nursing students from the four main nursing schools in Singapore. The use of similar vignettes as those by Chong et al. (2016) [17] allows us to make meaningful comparison in terms of mental health literacy with the general population. The study also included factors such as intra-nursing school training in psychiatric nursing and continuum beliefs and explored their relationship with mental health literacy. To the best of our knowledge, no other study has looked into these variables in this area. One limitation, however, pertains to the use of vignettes that described persons with prototypical and severe symptoms, may not reflect real-life cases. Given that this is a group of healthcare professionalsto-be, it may be crucial to explore their ability to recognize more complicated cases such as those with comorbidities, and those with prodromal or uncommon symptoms. 


\section{Conclusion}

The current study highlighted the need for further training and education to raise mental health literacy among the nursing student population, particularly in schizophrenia and alcohol abuse although this group performed better in terms of recognition across all five mental diagnoses compared to the general population. Our study also revealed that slightly more than $50 \%$ of the students agreed in a symptom continuum from mental health to mental illness. Nursing schools and placement institutions may have to play an important role to ensure that their students are mindful of such continuum belief that could possibly influence their recognition for mental disorders.

\section{Acknowledgements}

We would like to thank the nursing institutions involved for making this study possible.

\section{Funding}

This research is supported by the Singapore Ministry of Health's National Medical Research Council under the Centre Grant Programme (Grant No.: NMRC/CG/004/2013).

\section{Availability of data and materials}

For access to data, please approach Associate Professor Mythily

Subramaniam via mythily@imh.com.sg.

\section{Consent for publication}

Not applicable.

\section{Authors' contributions}

LSES wrote the first draft of the article and conducted statistical analyses. HLO and BYC made substantial contribution to the acquisition of data and provided intellectual input. EA had assisted in the analysis and interpretation of data. HX, JW, SAC and MS had made substantial contribution to conception and design and provided intellectual input. All authors have given final approval of the version to be published.

\section{Ethics approval and consent to participate}

The study was approved by the ethics committee of the Domain Specific Review Board of the National Healthcare Group, Singapore. All student participants have provided online consent to the study.

\section{Competing interests}

The authors declare that they have no competing interests.

\section{Publisher's Note}

Springer Nature remains neutral with regard to jurisdictional claims in published maps and institutional affiliations.

\section{Author details}

${ }^{1}$ Research Division, Institute of Mental Health, Singapore, Singapore. ${ }^{2}$ Nursing Administration, Institute of Mental Health, Singapore, Singapore.

Received: 7 December 2016 Accepted: 26 July 2017

Published online: 07 August 2017

\section{References}

1. Institute of Medicine. Health literacy: a prescription to end confusion. Washington DC: Institute of Medicine, Board on Neuroscience and Behavioral Health, Committee on Health literacy; 2004b.

2. Kessler RC, et al. Lifetime and 12-month prevalence of DSM-III-R psychiatric disorders in the United States. Results from the National Comorbidity Survey. Arch Gen Psychiatry. 1994;51(1):8-19.
3. Whiteford HA, et al. The global burden of mental, neurological and substance use disorders: an analysis from the global burden of disease study 2010. PLoS One. 2015;10(2):e0116820.

4. Jorm AF. Mental health literacy. Br J Psychiatry. 2000;177(5):396.

5. Jorm AF, et al. "mental health literacy": a survey of the public's ability to recognise mental disorders and their beliefs about the effectiveness of treatment. Med J Aust. 1997;166(4):182-6.

6. Glick ID. Undiagnosed bipolar disorder: new syndromes and new treatments. Prim Care Companion J Clin Psychiatry. 2004;6(1):27-33.

7. Bor JS. Among the elderly, many mental illnesses go undiagnosed. Health Aff (Millwood). 2015;34(5):727-31.

8. Lappalainen-Lehto R, Seppa K, Nordback I. Cutting down substance abusepresent state and visions among surgeons and nurses. Addict Behav. 2005;30(5):1013-8

9. Mulsant BH, Ganguli M. Epidemiology and diagnosis of depression in late life. J Clin Psychiatry. 1999;60(Suppl 20):9-15.

10. Yeo SG, et al. Mental health literacy survey of psychiatrically and generally trained nurses employed in a Singapore psychiatric hospital. Int J Nurs Pract. 2001;7(6):414-21.

11. Crawford G, et al. Mental health first aid training for nursing students: a protocol for a pragmatic randomised controlled trial in a large university. BMC Psychiatry. 2015;15(1):26.

12. van Os J, et al. A systematic review and meta-analysis of the psychosis continuum: evidence for a psychosis proneness-persistence-impairment model of psychotic disorder. Psychol Med. 2009;39(2):179-95.

13. Johns LC, van Os J. The continuity of psychotic experiences in the general population. Clin Psychol Rev. 2001;21(8):1125-41.

14. Schomerus $G$, Matschinger $H$, Angermeyer MC. Continuum beliefs and stigmatizing attitudes towards persons with schizophrenia, depression and alcohol dependence. Psychiatry Res. 2013;209(3):665-9.

15. Makowski AC, et al. Continuum beliefs in the stigma process regarding persons with schizophrenia and depression: results of path analyses. PeerJ. 2016:4:e2360.

16. Link BG, Phelan JC. Conceptualizing Stigma. Annu Rev Sociol. 2001:27(1):363-85.

17. Chong SA, et al. Recognition of mental disorders among a multiracial population in Southeast Asia. BMC Psychiatry. 2016:16:121.

18. Chong SA, et al. A population-based survey of mental disorders in Singapore. Ann Acad Med Singap. 2012;41(2):49-66.

19. Subramaniam $M$, et al. Prevalence of dementia in people aged 60 years and above: results from the WiSE study. J Alzheimers Dis. 2015;45(4):1127-38.

20. Verma $\mathrm{S}$, et al. Symptomatic and functional remission in patients with first-episode psychosis. Acta Psychiatr Scand. 2012;126(4):282-9.

21. Grant BF, Harford TC. Comorbidity between DSM-IV alcohol use disorders and major depression: results of a national survey. Drug Alcohol Depend. 1995:39(3):197-206.

22. Kessler RC, et al. Llfetime co-occurrence of dsm-iii-r alcohol abuse and dependence with other psychiatric disorders in the national comorbidity survey. Arch Gen Psychiatry. 1997;54(4):313-21.

23. Kuria MW, et al. The association between alcohol dependence and depression before and after treatment for alcohol dependence. ISRN Psychiatry. 2012;2012:482802.

24. Subramaniam $M$, et al. Continuum beliefs and stigmatising beliefs about mental illness: results from an Asian community survey. BMJ Open. 2017;7(4)

25. Angermeyer MC, et al. Continuum beliefs and attitudes towards people with mental illness: results from a national survey in France. Int J Soc Psychiatry. 2015;61(3):297-303.

26. Creech SK. Changes in attitudes about mental illness among nursing students following a psychiatric affiliation. J Psychiatr Nurs Ment Health Serv. 1977:15(6):9-14.

27. Wallach HS. Changes in attitudes towards mental illness following exposure. Community Ment Health J. 2004;40(3):235-48.

28. Baumann AE. Stigmatization, social distance and exclusion because of mental illness: the individual with mental illness as a 'stranger'. Int Rev Psychiatry. 2007;19(2):131-5.

29. Corrigan PW, et al. Changing public stigma with continuum beliefs. J Ment Health. 2016:1-8. 